\title{
Factors Influencing Rural Toursim Development Incase of Srikakulam District-AP
}

\author{
Gopalakrishna Vakamullu, Koppala Venugopal, D. Vishnu Murty
}

\begin{abstract}
Rural development in general, is much associated with its economic growth backed up with the maximum utilization of rural resources and the government's support through welfare schemes and other provisions. The transmission of urbanization in the way of rural development, has been at the pace of developing economy. Though the resources of rural environment is confined with agricultural and some other professional sectors, certain destinations amalgamated with spiritual confidence, unique ambience, coastal beauty and historical tracks have been popularly known by a limited people which is found to be focused for the economic development of rural India. As the specific objectives of identifying particular destinations with their core competencies and evaluating its marketing opportunities and assessing the tourists behavior, this study proceeded with a method mix of descriptive, cross-sectional design with convince sampling of non-probability. A standard questionnaire targeted to the population of tourists with the determined size backed up with all measurement tests were executed. The results with the establishment of interpretation on the required practices of rural tourism development were exposed with multiple regression analysis. Specific recommendations with the management implication have been offered at the stand point of government policy modification, destination marketing practices, infrastructural requirement and tourism delight.
\end{abstract}

Key Words: Rural development, Tourism destination, Marketing practices, Tourist satisfaction

\section{INTRODUCTION}

Rural being imperative for many industries that focus to make the most of rural resources and turn into productive and effective mode which adds to economic growth. The resources prevailing at the rural and tribal places are abundant and made utilized so far for agricultural development majorly. However certain attributes are yet to be concentrated such as tourism development at the stand point of particular unique features and resources of any rural place.

Tourism destination with respect to spirituality, natural landscapes, organic products, handicrafts and cultural adroit can be turned as a driving face for the tourist to be attracted. Root of the rural places are visited by many for the reason that there is no substitute as such in urban places. But all are operated an unorganized sector and organized promotions to develop in line with tourism or destination management and administration.

Vara Prasad \& Sundari, (2012), in their research explored the strength of rural tourism and its significance positively

Revised Manuscript Received on December 30, 2019.

Gopalakrishna Vakamullu, Assistant Professor, Department of MBA, Aditya Institute of Technology and Management, Tekkali, Srikakulam, AP, India

Dr. Koppala Venugopal, Professor \& HOD, Department of MBA, Aditya Institute of Technology and Management, Tekkali, Srikakulam, AP, India

Dr. D. Vishnu Murty, Dean and Professor, Aditya Institute of Technology and Management, Tekkali, Srikakulam, AP, India on the growth of economic and contribution to GDP, additionally focused on secured and excitement destinations which could be enjoyed by certain segment with good majority.

Science the rural credentials that give a leverage to the tourism development have yet to be promoted in an effective manner, the marketing role has to be emphasized to explore the features of destinations to the exciting as well as new customers (Anandan.D, 2004).

The stakeholders relating to Indian Tourism Industry such as central agencies, governments and private sector players are continuously consulted by particular ministry in designing productive policies with efficacious efforts of niche tourism promotion with rural cruise, medical and ecotourism further makes the industry growing with campaign of "Incredible India". The arrangements of AP tourism department are highly motivated to those who want to visit the world with all comforts.

A healthy annual growth of $6.9 \%$ reaching 32.05 lack crore by 2028, is expected from Indian Tourism Industry backed by the present achievement of sustainable contribution i.e. 16.91 lack crore in 2018, which create 42.673 million jobs. It is notable point that industry adds $9.2 \%$ to GDP and expected to grow up to $9.9 \%$ by 2023 (World Travel and Tourism Council, 2018). A considerable growth is significantly expected from medical tourism with the growth of US\$ 7-8 billion by 2020 with its causality from foreign patients' market also.

India being stood at 34 th position among 140 countries in 2019 , can be considered as significant growth with $25 \%$ where in competitiveness gained more credibility with 13th rank and cultural resources and business travel with 8th rank (Travel and Tourism Competitiveness report, 2019).

Srikakulam as one of the backward districts of Andhra Pradesh ha innumerable rural destinations serving distinguished teachers of excitement delight the tourists which is the central and focused objective of tourism department by adapting the service marketing approach for achieving great success. To focus more on the rural attributes of the district, there are a good number of places associated and famous with their dexterous competencies of spiritual, cultural, agricultural, natural and recreational destinations segment wise established in line with historical and resourceful background. It is also found through observations and previous studies from other states that there are certain factors influencing on the elevation of these destinations. This research is taken up aiming at possible factors and to analyze the extent that each factor influences on rural tourism destination. 


\section{Factors Influencing Rural Toursim Development Incase of Srikakulam District-AP}

\section{OBJECTIVES OF THE STUDY}

The objectives of the research are

- To identify the potential tourism destinations with their core competencies in Srikakulam district.

- To assess the factors influencing the growth of rural tourism destinations in Srikakulam district.

\section{RELATED LITERATURE REVIEW}

Attitude of tourists have been found significant implication on measuring the tourism potentiality where the successful strategies can be prepared on the basis of relaxation, visits and vacation destinations attracted and motivated by consumers attitude out of the knowledge supplemented by destinations, Malhotra (2005)

Planning, organizing, marketing and research as imperative factors should properly being connected to the contribution to tourism development which leads to the prosperity of nation Bhatia A.K, (1982)

Bhardwaj and Manjula Chaudhary, (1997) noted that the diversity of different activities for the industry development depends more on tourism planning which has to connect the strategies with the factors effecting and balance them because unexpected conflicts and investable social and political problems are to be overcome for the safety and life style of tourism especially from foreign market.

Trending for rural tourism is considered to be the ambience and association of ecological traits have been addressed by Ravi Bhushan Kumar (1995) while studying coastal Kerala where the environmental deterioration should be focused and Ravee Chauhan (2006) proclaimed that there are no specific government policies on eco-tourism but certain guidelines for environmental protection campaign have been catered.

As Bishwanath Ghosh (2001) stated the ways to generate money through business excellence in any reason depends upon agriculture, industrial, and tourism development. The similar importance to the tourism industry developed with security, landscapes, hospitality and economical credentials.

Science the competitiveness has highly correlated with the survival of tourism sector. The importance for the quality improvement along with the service deliveries and skills such as hospitality, catering, transporting, guiding etc., for which the measures in the way of appropriate and specific training is to be provided not only to attract the foreign tourists but also to attract the urban Indian tourists towards rural unique propositions Praveen Sethi (2002)

Typically, the social roles of people's impact on their attitudes towards rural destinations with the independent factors of society norms, thoughts, beliefs, traditions and culture, Kumar Sandeep and Kumar Vinod (2014), the researchers also stated the positive and negative factors influencing tourism development. Yashodhara, Jain. (1998), also suggested that " social and cultural benefits should be more focused rather than economic benefits while judging the tourism benefits; in addition there will be high exchange of communication habits, traditions, culture and life styles which roots to socio cultural development of either side

Studies on medical tourism developed by Suman Kumar Dawn and Swati Pal (2011), have explored the importance and image of Indian medical tourism destinations producing and promoting certain products of high quality leads to safety treatment at penetrated pricing and many foreign tourists are attracted towards nature cure, yoga, organic and herbal usage which are mostly produced in rural destinations

Though the traditional promotions through mass media are well used by rural destinations. The trendy promotional strategies through online and e-marketing tools such as website marketing, social media marketing, e-marketing, banner advertisement etc., (Venugopal K, et al. 2019). Renu Malra (2013) also stated in her studies previously with pull and push strategy.

Through the literature and empirical evidences dealt, the independent variables taken from the crux are drive for economic growth, Planning, Training, Substitution to urban destinations, Environmental competencies, e- marketing promotions, medical and nutritional tourism, Socio-cultural factors, resources utilization and evil effects and the dependent variable is the performance of rural tourism destinations. The conceptual frame work portrayed down under can be demonstrative enough to understand the relationship between independent and dependents variables. Independent Variable

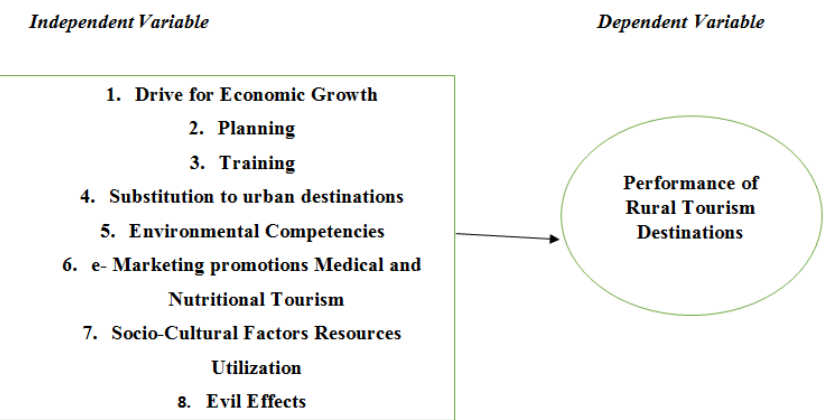

Figure: Conceptual Framework (Source: Researchers review)

\section{METHODOLOGY}

The study area of the research is Srikakulam district of recently formed Andhra Pradesh state which has high potentiality of attracting different tourism communities of science. It is considered has a hub of religion and spiritual tourism where different people from different religion visit to worship the temples, churches, mosques and Buddha stupas.

Research design of the study is addressed by applying descriptive and explanatory research type. Moreover, the constraints, and opportunities in general will be covered by descriptive research design. The design of this study was cross-sectional in which data was shot at a single moment and analyzed to get findings. To address the objectives stated, a standard questionnaire, interview, observation and focus group discussion were used as data gathering methods. Mixed research paradigms of qualitative and quantitative methods were applied in this research to analyze data collected from different sources. In line with this prevailing fact and meeting the research objective, the quantitative approach featured much. 
The target population of the study was the tourists who visit different tourism destinations of distinguished rural places in Srikakulam district which are considered to be unlisted since the size is infinitive. The study used 260 of total population and convenience sampling technique to select the respondents from tourists that visit rural destinations.

\section{ANALYSIS\& RESULTS}

3.3 Coefficients $^{\mathrm{a}}$

\begin{tabular}{|c|c|c|c|c|c|}
\hline \multirow[t]{2}{*}{ Model } & \multicolumn{2}{|c|}{$\begin{array}{l}\text { Unstandardized } \\
\text { Coefficients }\end{array}$} & $\begin{array}{l}\text { Standardized } \\
\text { Coefficients }\end{array}$ & \multirow[t]{2}{*}{$\mathrm{T}$} & \multirow[t]{2}{*}{ Sig. } \\
\hline & $\mathrm{B}$ & Std. Error & Beta & & \\
\hline (Constant) & 2.893 & .645 & & 4.488 & .000 \\
\hline $\begin{array}{l}\text { 1. Rural destinations contributes to } \\
\text { economic growth }\end{array}$ & -.034 & .099 & -.024 & -.344 & .731 \\
\hline 2. Planning of tourism development for rural & .002 & .104 & .001 & .015 & .988 \\
\hline $\begin{array}{l}\text { 3. Training to be given to the marketers of } \\
\text { rural tourism }\end{array}$ & .031 & .092 & .026 & .341 & .733 \\
\hline $\begin{array}{l}\text { 4. Rural destinations as a better alternative } \\
\text { destinations }\end{array}$ & -.102 & .095 & -.086 & -1.066 & .288 \\
\hline $\begin{array}{l}\text { 5. Better environment than urban tourism } \\
\text { places }\end{array}$ & .078 & .097 & .061 & .803 & .423 \\
\hline $\begin{array}{l}\text { 6. Importance of e- marketing promotions } \\
\text { for rural tourism Development }\end{array}$ & .175 & .087 & .167 & 2.010 & .046 \\
\hline $\begin{array}{l}\text { 7. Medical tourism as an exceptional option } \\
\text { in rural places }\end{array}$ & .127 & .080 & .114 & 1.579 & .116 \\
\hline $\begin{array}{l}\text { 8. Socio-cultural factors influences } \\
\text { positively }\end{array}$ & .038 & .091 & .030 & .424 & 672 \\
\hline $\begin{array}{l}\text { 9. Resources unused can be utilized properly } \\
\text { through rural tourism }\end{array}$ & -.154 & .111 & -.108 & -1.381 & .169 \\
\hline 10. Evil effects of rural tourism & .097 & .105 & .068 & .921 & .358 \\
\hline
\end{tabular}

a. Dependent Variable: Overall performance of your business unit has increased since 2014/15

$y=\alpha+\beta 1 \times 1+\beta 2 \times 2+\beta 3 \times 3+\beta 4 \times 4+\beta 5 \times 5+\beta 6 \times 6+\beta 7$ $\mathrm{x} 7+\beta 8 \mathrm{x} 8$

Where

$\mathrm{y}=$ Dependent variable

$\mathrm{x}=$ Independent variable

$\alpha=$ Intercept

$\beta=$ Estimate

As per the Coefficients retrieved from table 3.3, the formula can be as follows

Rural tourism performance $(\mathrm{DV})=2.893+(-.024)$ Economic growth $+(.001)$ Planning $+(.026)$ Training $+(-$ .086) Alternative Destinations $+(.061)$ Better Environment $+(.167)$ e-marketing $+(.114)$ Medical Tourism $+(.030)$ Socio cultural activities $+(-.108)$ Resources $+(.068)$ Evil effects.

Rural tourism performance with respect to the RTF 1(Rural destinations contributes to economic growth) is 2.869 (2.893 - 0.024); if IFC1 increases by one unit, the overall performance is increased by 2.869 .

Likewise if the predictors RTF2, RTF3, RTF4, RTF5, RTF6, RTF7, RTF8, RTF9 and RTF10 are increased by one unit, the dependent variable i.e. overall performance is increased for RTF 2 (Planning of tourism development for rural) by 2.894; IFC 3 (Training to be given to the marketers of rural tourism) by 2.919 ; IFC 4 (Rural destinations as a better alternative destinations) by 2.033; IFC 5 (Better environment than urban tourism places) by 2.954; IFC 6 (Importance of e- marketing promotions) by 3.06; IFC 7 (Medical tourism as an exceptional option in rural places) by 3.007; IFC 8 (Socio-cultural factors influences positively) by 2.923; IFC 9 (Resources unused can be utilized properly through rural tourism) by 2.785 and IFC 10 (Evil effects of rural tourism) by 2.961 .

\section{FINDINGS}

It can be understood that the importance being given by tourists at the higher size for the promotions to be distributed through internet or online sources with the highest weightage of 3.06, similarly most of the tourists rigid rural places for the purpose of medicines and organic products majorly some of the forest places like Seethampeta, mandasa are visited by many people for the same reason.

Interestingly, the most decreased value of 2.003 credited by the response of tourists in consideration with rural destinations have better environment. They might have absolutely felt that the comparison has no impact of absolute differential threshold.

As far as the economic contribution by rural tourism development is concerned the respondents shown negative impact with its $\beta$ value of -.024 which indicates that the rural tourism has low pace of development from its tourism destination image in fact most of the tourists visit for their benefits rather than contributing to rural growth. 


\section{Factors Influencing Rural Toursim Development Incase of Srikakulam District-AP}

The factors of proper and maximum utilization of rural natural resources which are so far unused has got a negative value of -.108 which proves that the natural resources exist as it is could be an exceptional image centered factors such as landscapes, nature, cultural symbols etc., should not get organized and altered.

\section{RECOMMENDATIONS\& CONCLUSION}

Certain decisions on policies which will develop Micro and Small enterprises with respects to the destinations concern of rural tourism promoted and developed by government and tourism authorities could improve the 18 business size of particular places so as to find the increasing economic growth.

Planning as a mandatory, the destination managers and administrators should be well planned with the exploration of destination's core competencies such as spiritual, medical, nature and cultural based destinations.

Professionalism should be executed in every part of tourism management and a proper training for certain stakeholder should be given to treat tourists and pilgrims in a better way. It is found that most of the pilgrims are effected by the authorities of spiritual destination.

Originality of destination is found well appreciated so the nurtured and organized are altered structure of rural ambience may be ignored.

Use of internet is highly accessible and total information 25 through an exclusive website can make a personalized communication with tourists and the intermediates with deceptive nature may be considerably reduced.

Most of the people focus on the practices for the good health in the way of millet diet, organic products, natural products, ayurvedic products, verbal based products and minor forest products (MFP), for the reason that they visit certain places the need of producing the same may increase the level of transactions and leads to growth.

\section{REFERENCES}

1 Ajitha.S: "Tourism - The Other Side", The Journal of Business Studies, Vol.2, No.1, 2004, pgp.87.

2 Anandan: "Marketing of tourism products", The Journal of Business Studies, Vol.2 No.1, 2004, P.94.

3 Archana Bhatia: "SWOT Analysis of Indian tourism Industry", International Journal of Application or Innovation in Engineering \& Management (IJAIEM), Vol.12, Issue - 12, 2013, pp.44-49.

4 Aschalew Adane., Seyar Yassin., Bamnet Letibelu and K. Venugopal (2018) "Assessment Of Hotel Seasonality; Causes, Challenges \& Marketing Strategies to Deal with: In Case of Selected Hotels of Amhara National Regional State"., International Journal of Innovative Research and Practices( IJIRP),Volume 6, Issue 1, January 2018, PP: 8-18

5 Batra, G.S, Dangwal, R.C: "Tourism Promotion and Development" Deep and Deep

6 Publication, New Delhi, 2000.

7 Bhardwaj, D.S., and Chaudhary, Manjula: "Contemporary Issues in Tourism”, Himalaya publishing house, Mumbai, 1997.

8 Bhatia A.K: "Tourism Management and Marketing", Sterling Publishers, New Delhi, 1997, pp.39-41.

9 Chauhan, Ravee: "Eco Tourisms-Trends and Challenges", Vista International Publishing House, New Delhi, 2006, p.241.

10 Jacob Robinet, Joseph Sindhu and Philip Anoop: "Indian Tourism Products", Abhijeet Publications, New Delhi, 2007, pp.11-12.

11 Jain, Yashodhara: "Tourism Development (Problems and Prospects of Tourism)", A.P.H. Publishing Corporation Darya Gang, New Delhi, 1998.

12 Koppala Venugopal and Vishnu Murty D (2019) Impact of emarketing promotions on the performance of Religious Tourism: In case of Srikakulam district, A. P, India" International Journal of Engineering and Advanced Technology, Volume-8, Issue-6S3, September 2019, PP:1289-1292

Kumar, Ravi Bhushan: "Coastal Tourism and Environment", APH Publishing Corporation Darya Gang, New Delhi, 1995, pp.161-233.

Kumar Sandeep and Kumar Vinod: "Perception of Socio-Culture Impacts of Tourism: A Sociological Review", International Research Journal of Social Sciences, Vol. 3, No.2, 2014, pp.40-43.

15 Malhotra, R.K:" Tourism Planning and Management”, Anmo Publications Pvt. Ltd., New Delhi, 2005, p. 333

Manoharan Nair K: "Tourism Marketing - A SWOT analysis", The Journal of Business Studies, Vol.2 No.1, 2004, pp. 92.

Munish Tiwari: "Making of Indian Tourism in 21st Century: Challenges and Prospects", International Journal of Physical and Social Sciences, Vol.2, Issue - 5, 2012, pp.309-318.

Ranbir Singh: "Challenges Faced by Tourism Industry of Haryana", International Journal of Management Research and Review, Vol.2, Issue-11, 2012, pp.1875-1880. Shaheeda Banu: "Emerging Trends in Tourism Marketing-With Special Reference to Karnataka as Tourism Destination", Global Journal of Commerce and Management Perspective, Vol. 1, No. 2, 2012, pp.19-25.

19 Remanan. K: "Evils of Tourism", the Journal of Business Studies, Vol.2, No.1, 2004, pp. 85.

20 Renu Malra: "Online Tourism Marketing”, Asia Pacific Journal of Marketing \& Management Review, Vol. 2, No.7, 2013, pp.150-156. Santosh Ranganath N, Venugopal K, (2011), "Rural Entrepreneurship Challenges and Opportunities: An Indian Context", Indian Journal of Applied Research, Volume 1, Issue 2, November 2011, pp. 65-68.

Sethi, Praveen: "Millennium Trends in Travel and Tourism", Rajat Publications, New Delhi, 2002, p. 300.

23 Varaprasad and Sundari: "Indian perspective on Tourism (Interventions and Drivers)", International Journal of Research in Management, Vol. 1, Issue - 2, 2012, pp. 115-127 https://en.wikipedia.org/wiki/World_Tourism_Organization https://en.wikipedia.org/wiki/Tourism_in_India http://aptourismsrikakulam.blogspot.com/ 